\title{
Enhancing the Oral Bioavailability of Peptide Drugs by using Chemical Modification and Other Approaches
}

\section{Naibo Yin 1 , Margaret A Brimble ${ }^{2}$, Paul WR Harris² and Jingyuan Wen ${ }^{1 *}$}

${ }^{1}$ School of Pharmacy, University of Auckland, Auckland, New Zealand

${ }^{2} \mathrm{~S} c h o o l$ of Chemical Science, University of Auckland, Auckland, New Zealand

\begin{abstract}
In regards to patient compliance for drug delivery, oral drug delivery is generally the preferred route of administration. However, parental injection of peptide drugs has always been the primary method of peptide drug administration. This is a result of the poor oral bioavailability of peptide drugs, which are typically under $1 \%$. The degradation of peptides in the gastrointestinal $(\mathrm{Gl})$ tract by peptidase enzymes and harsh $\mathrm{pH}$, combined with the poor intestinal mucosal penetration properties of the non-drug-like peptide drugs have been identified as the major barriers towards improving the oral bioavailability. Nevertheless, oral delivery of peptide drug presents a significant challenge due to the enzymatic degradation by enzymes in the GI tract and the poor penetration of the peptides across gastro-intestinal epithelium membranes, particularly for adults. Therefore, a novel peptide drug analogue or pro-drug that both protect peptide drugs from degradation by the enzymes in the Gl tract that also improves its penetration across the intestinal epithelium membrane would greatly advance the development of peptide drugs as effective candidates for the treatment of various diseases. So far several approaches are being investigated to improve the oral bioavailability of peptide drugs by different researchers. Indications suggest that chemical modification such as incorporation of unnatural amino acids, unnatural peptide bonds, cyclisation and pro-drug approaches as well as nanoparticulates systems such as nanoparticles and microemulsions offer great potential for improvement and likelihood of enabling peptide drug to be administered orally. This review will focus on the chemical modification methods and other approaches (such as using variable nanoparticular delivery systems), that could be used to overcome the barriers involved in low oral bioavailability of peptide drugs.
\end{abstract}

Keywords: Gastrointestinal; Lymphatic system; Peptide drugs

\section{Introduction}

Peptides are composed of short chains of amino acid monomers linked together via peptide bonds and occur naturally in the human body. Peptides are very specific in activity when compared to small molecules when used as a drug candidate. Generally having fewer side effects, peptides have become popular candidates for drug design. In 2007 , there are about 60 approved peptide drugs that are in clinical use and have generated approximately $\$ 13$ billion USD as of 2010 [1]. Another 140 peptide candidates are in clinical trials, as well as another 500 to 600 in pre-clinical development [1]. The difficulty associated with marketing peptide drugs, however, is the low oral bioavailability as a result of physical and biochemical barriers of the gastro intestinal tract forcing invasive parental delivery methods to be the only practical method of delivery. Such parental injection methods include: intravenous, intramuscular and subcutaneous injections. Unfortunately, parental delivery methods make administration of peptide drugs difficult and painful, which leads to lower patient compliance and ultimately, reduced popularity of using peptide drugs on a frequent basis. Oral administration, on the other hand, would offer easy, convenient administration that can be sold over the counter.

Oral administration of peptide drugs is severely hindered by the physical, biological and chemical barriers of the gastrointestinal (GI) tract. Such chemical, biological and physical barriers present in the GI tract serve to primarily protect the body from pathogens, antigens or any other harmful substances while allowing both digestion and absorption of ingested nutrients or fluids for essential body functions. The chemical barrier for peptide drug delivery is attributed to the proteases and the low $\mathrm{pH}$ environments of the stomach that are both essential for the digestion of proteins required for the successful absorption of amino acids [2]. These same proteases that facilitate the hydrolytic degradation of protein in food, however, are also able to facilitate the hydrolytic degradation of peptide-based drugs due to their similarities in chemical structure and functional groups. Major gastrointestinal proteases that are involved in the process of hydrolysis of peptide or protein into amino acids include: pepsin, chymotrypsin, pepsin, trypsin, carboxypeptidase and aminopeptidases [2]. The absorption of proteins and peptides across the intestinal membrane as depicted in fig. 1 is also limited by the physical barriers presented by the unstirred water/mucous layer (UWL), the epithelial membrane of enterocytes (transcellular route) and the tight junctions between the apical ends of the epithelial cells (paracellular route). Furthermore, drug can be uptaken into the blood by receptor mediated endocytosis, or uptaken into the lymphatic system via $\mathrm{m}$ cells located at the Peyer's patches. The intestinal epithelial cells are specialised in the absorption of amino acids or dipeptides as opposed to the uptake of larger peptide and proteins. Furthermore, efflux systems located on the surface of intestinal epithelial cells as well as potential metabolism of any peptide drugs inside the intestinal epithelial and liver cells serve to further decrease the oral bioavailability of peptide drugs before it enters the systemic circulation. Micro-organisms located in the intestinal lumen are able to breakdown peptides by the release of peptide metabolising enzymes. This presents a biological barrier for peptide drug absorption $[2,3]$. As a result of the above factors influencing the absorption and stability of peptide drugs in the GI tract, peptide drugs generally show less than $1 \%$ oral bioavailability and therefore considered unacceptable for clinical usage as oral dosage forms [4,5]. Many different methods

*Corresponding author: Jingyuan Wen, The School of Pharmacy, University of Auckland, Grafton, Auckland 1023, New Zealand, Tel: +64 9923 2762; Fax: +64 9 367 7192; E-mail: j.wen@auckland.ac.nz

Received October 17, 2014; Accepted November 25, 2014; Published November 27, 2014

Citation: Yin N, Brimble MA, Harris PWR, Wen J (2014) Enhancing the Oral Bioavailability of Peptide Drugs by using Chemical Modification and Other Approaches. Med chem 4: 763-769. doi:10.4172/2161-0444.1000227

Copyright: (c) 2014 Yin N, et al. This is an open-access article distributed under the terms of the Creative Commons Attribution License, which permits unrestricted use, distribution, and reproduction in any medium, provided the original author and source are credited. 
including chemical modification of peptides have been established as attempts to improve oral bioavailability of peptide drugs.

\section{Chemical Modifications}

\section{Peptide analogues}

Peptide analogues or peptidomimetics are peptide sequences utilizing unnatural amino acids or unnatural peptide bond linkages between amino acids. Such modifications creates a resulting peptide sequence that is less susceptible to enzymatic degradation as naturally occurring proteases are designed to catalyse reactions involving natural peptides and natural peptide bonds. One difficulty in this approach is the activity of the drug must be retained. Unnatural amino acids and unnatural sterics of a peptidomimetic are required to be able to interact with the original intended receptor or targets. $\mathrm{N}$-alkylation and $\alpha$-alkylation of amino acids can provide steric hindrance against enzymatic degradation. Modification of peptide bonds can create bonds between amino acids that are resistant to peptidases that cleave peptides at peptide bonds to liberate amino acids. Examples of biologically active and enzymatically stable peptide bond substitutes previously used include: reduced amide bond, alkene, hydroxyalkene, hydroxyethylamino, dihydroxyethylene and thioamides [6]. Reversal of stereochemistry from natural $\mathrm{D}$-amino acids to $\mathrm{L}$-amino acids has shown to increase resistance to proteases while retaining activity. Increase in lipophilicity or decrease in hydrogen bonding potential by chemical modification of a peptide can improve the cell penetrating ability of a peptide. It has been shown that a chain of methylphenylalanine had improved caco- 2 cell culture penetration compared to the same peptide chain of phenylalanine [7]. Glucagon-like peptide-1 was found to be enzymatically cleaved at $\mathrm{ala}^{2}$ by Joseph, J.W et al (2000). Replacement of ala $^{2}$ with D-ala ${ }^{2}$ (chemical structures shown in Figure 2) showed an increase in drug stability, half-life and activity [8]. Mimicking the shape of secondary structures of peptides while changing the functional group of a peptide chain can also be achieved through the use of peptidomimetics. This can help increase enzymatic stability without the loss of activity.

\section{Peptide pro-drug conjugates}

Pro-drugs are conjugates of drugs that can be easily metabolized using enzymes in the human body or under physiological conditions to release the natural drug and non-toxic by-products. Pro-drugs for oral peptide delivery are designed to remain in the inactive pro-drug form while in the GI tract to be protected from by degradation in GI

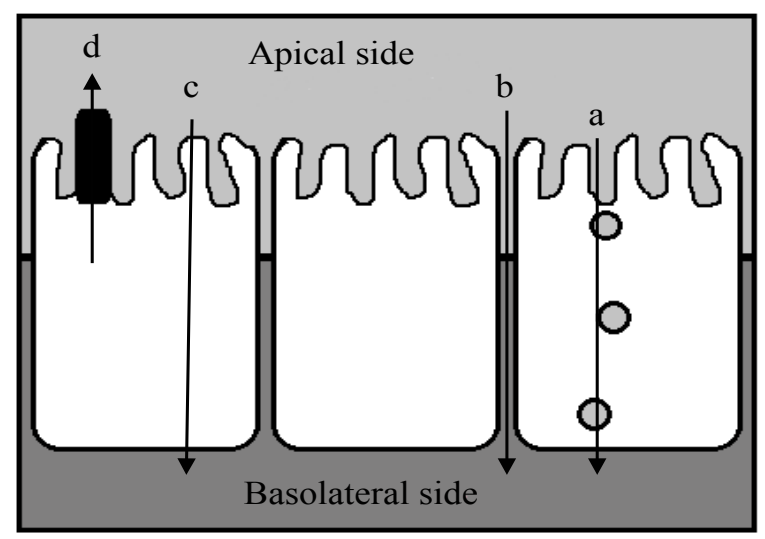

Figure 1: Diagram illustrating different pathways of drug transport across intestinal epithelial membrane: a) endocytosis pathway b) paracellular pathway c) transcellular pathway d) protein removal via protein efflux pump.<smiles>C[C](N)C(=O)O</smiles><smiles>C[C@H](N)C(=O)O</smiles>

Figure 2: Chemical structure of: a) L-ala and b) D-ala

conditions. Pro-drugs can also improve the physical properties of a drug to increase uptake through the intestinal cell membrane. After bypassing these barriers, the drug is released from the pro-drug by metabolism. Therefore, readily cleavable linkers have been developed to maximise the drug recovery rate within the body. Lipophilic moieties such as long fatty acid chains have been common conjugates used for increasing the lipophilicity of hydrophilic peptides to enhance uptake. The conjugation of palmitic acid to Leucine ${ }^{5}$-enkephalin via an ester bond combined with the use of nanoparticle GCPQ formulation methods has shown an increase in activity and duration of effect compared to the unconjugated peptide in the same nanoparticle formulation [9]. Another example of increasing the lipophilicity of a peptide drug by conjugation of a fatty acid moiety is the attachment of 1,3-dipalmitoylglycerol to insulin by an ester bond [10]. This study showed an increase in intestinal penetration of the conjugate compared to the native as well as an increase in stability to enzymatic degradation. Covalent attachment of a dimethylmaleic anhydride analogue, 3,4-bis (decylthiomethyl)-2,5-furandione to leu-enkephalin showed increased resistance to aminopeptidase, which is the primary enzyme responsible for cleavage of natural leu-enkephalin. The area under curve (AUC) of the lipid conjugated group was found to be 21 folds greater than that of the unconjugated leu-enkephalin group and this was attributed to the increase in membrane penetration of the more lipophilic pro-drug [11]. Conjugation of a glutathione-methionine analogue in another study, to an L-dopa analogue displayed stability towards degradation in the stomach, improved absorption through the intestinal cell membrane as well as spontaneous cleavage and release of L-dopa in plasma conditions in a study by Pinnen et al. (2012) [12]. The conjugation of low molecular weight chitosan to the anti-diabetes drug exendin- 4 showed high stability against enzymatic degradation due to the resulting charged nanoparticle-like structure formed. Exendin- 4 was conjugated to the low molecular weight chitosan backbone via an easily cleavable disulphide bond. Oral administration of the conjugate was shown to be absorbed into the blood and produced an anti-diabetes effect in type 2 diabetes rat models [13]. The attachment of short carbohydrate units to peptides can also improve intestinal mucosa penetration. Conjugation of lactose, galactose and glucose to the $\mathrm{N}$-terminus of the glutamic acid analogue of gonadotrophin release hormone and the $N$-terminus of the glutamine analogue of the same peptide showed an increase in caco- 2 cell penetration with the highest increase being lactose conjugated to the glutamic acid analogue showing a 7.2 fold increase in penetration [14]. Glucagon-like peptide-1 was diconjugated to biotin via lys ${ }^{26}$ and $\mathrm{lys}^{34}$ and the conjugate showed a significant increase of the drug AUC in rat models.

\section{Peptide Cyclic Pro-Drugs}

Another pro-drug strategy is the cyclisation of peptides, which can enhance the cell membrane penetrating ability of a linear peptide. The constrained stereochemistry of the cyclic pro-drugs is thought to be harder for proteases to recognise when compared to the linear, freely rotating peptides. As with all pro-drug strategies, recovery of the original drug is important. To improve the regeneration rate for the 
linear peptide cyclisation, readily cleavable linkers have been used in different studies. Coumarin-based linker (structure shown in Figure 3) for cyclic peptides has been shown to improve oral bioavailability for analogous of the tripeptide fibrinogen antagonist Arg-Gly-Asp. The coumarin-based cyclic prodrug has shown increase in lipophilicity as well as mucosal membrane penetration. The peptidomimetic prodrug was observed to be bioconverted into the peptidomimetic form and displayed antithrombotic activity in dog models [15]. Oral bioavailability was improved to $5-10 \%$ for the biotin conjugates [16]. It was found that cyclisation of a model hexapeptide (structure shown in Figure 4) caused conformational constraint, which leads to resistance to degradation by enzymes as well as enhanced penetration through a caco- 2 cell culture $[6,17]$. A recent NMR study conducted by Nielsen, D.S et al. (2014) successfully improved the oral absorption and bioavailability in rats of a heptapeptide by introduction of functional groups that help rigidify the overall cyclic peptide [18]. Hill T.A. et al. (2014) showed cyclohexaleucine composed of natural amino acids only was able to show a respectable $17 \%$ oral biavailability [19].

\section{PEGylation}

PEGylation of peptides involves the covalent attachment of polyethylene glycol (PEG), a non-toxic and non-immunogenic polymer, to a peptide. PEGylation is a commonly used strategy to enhance both pharmacokinetic properties as well as the pharmacodynamics properties of peptide-base drugs. PEG is an FDA approved compound and is non-toxic to use. PEGylation of compounds have also display decreased immune responses that can shorted drug half-life in the body. Earlier attempts at PEGlyation used smaller PEG chains of PEG $5 \mathrm{k}$ (molecular weight $5 \mathrm{kDa}$ ). More recent attempts at PEGylation of peptides conjugates uses longer PEG chains as more recent studies show greater activity for the longer PEG conjugates. PEGylation of peptides also can reduce immune responses associated with peptide drugs [20]. PEGylation of bovine lactoferrin (bLf) with PEG 20k and PEG 40k showed an increase in proteolysis resistance as well as a significant increase in intestinal uptake in mature rats [21]. In a continuation of this study, it was shown that both the PEG 20k and the PEG 40k
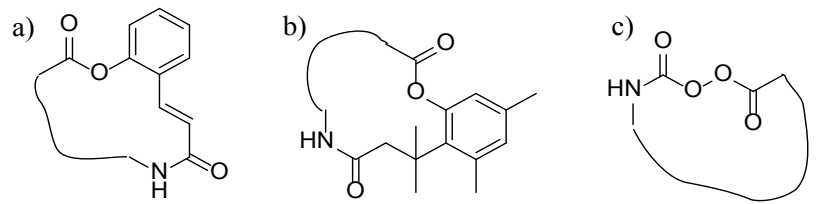

Figure 3: Structures of cyclic peptides using the: a) coumaric acid linker b) phenylpropionic acid linker and c) acylalkoxy linker
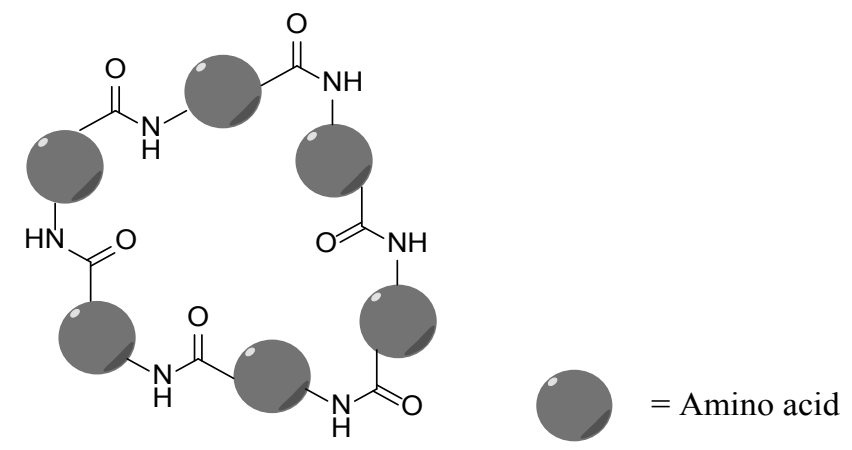

Figure 4: Structure of a cyclic hexapeptide conjugates showed an increase in biological activity compared to the unmodified bLf [22].

\section{Enyzymatic inhibitors}

Enzymatic inhibitors, as the name suggests, are capable of inactivating certain enzymes. Co-administration of enzyme inhibitors specific to the inactivation of GI peptidases that catalyse the metabolism of the administrated peptide drug with the administration of peptide drugs can serve to decrease the degradation of peptides in the GI tract and hence increase the oral bioavailability of peptide drugs. Enzyme inhibitors for peptide drug delivery can be classified into: polypeptide protease inhibitors, peptides, amino acids, and inhibitors that are not based on amino acids [23].

Maianti et al. (2014) was able to demonstrate in a study, the decrease in insulin degradation with the co-administration of protease inhibitors to improve the oral bioavailability of insulin. A significant decrease of blood glucose levels in both lean and diabetes induced obesity rat models as well as a significant increase in plasma insulin levels $20 \mathrm{~min}$ and $135 \mathrm{~min}$ post-administration of oral insulin with the peptidase inhibitor have been shown in this study [24]. Bacitracin is another enzyme inhibitor that has been used to inhibit the degradation of various therapeutic peptides including: insulin, metkephamid and buserelin [25-27]. Aminoboronic acid derivatives are amino acid based enzyme inhibitors, which have shown to successfully enhance peptide drug delivery in earlier studies but have decreased in usage due to pursuit of better alternatives [25]. Polypeptide protease inhibitors, on the other hand, have been used to a high extent as auxiliary agents to overcome the enzymatic barrier of orally administered therapeutic proteins due to their low toxicity and strong inhibitory activity [28]. A Peptidic enzyme inhibitor, aprotinin, is a small protein bovine pancreatic trypsin inhibitor commonly used to improve insulin bioavailability. Aprotinin was used by Kraeling $\mathrm{M}$ et al. to achieve $6.2 \%$ oral bioavailability of insulin, an increase from $5.0 \%$, which was observed using the same formulation approach without aprotinin [29]. Inhibition of enzymes however is known to cause side-effects such as systemic toxicity, disturbed digestion and hyperplasia of the pancreas [30].

\section{Absorption enhancers}

Another method used to improve peptide oral bioavailability is the co-administration of absorption enhancers. Absorption enhancers are a wide range of chemical compounds through a wide range of mechanisms. Absorption enhancers that have been reported in the literature with some success includes: ethylenediaminetetraacetic acid (EDTA), citric acid, salicylate, $\mathrm{N}$-acyl derivatives of collagen [31-33] cyclodextrins [34], sodium caprylate [35], sodium lauryl sulphate [36] and sodium taurocholate [37]. Absorption enhances act via different mechanisms to increase the penetration of peptides through intestinal cell membranes. Mechanisms of action for absorption enhancers includes: opening tight junctions, changing the membrane fluidity and changing the mucous viscosity $[38,39]$.

Chitosan acts as an absorption enhancer that is able to increase lactoferrin absorption and permeability through the intestinal membrane by opening the intercellular junctions [40]. One patent describes the use of an EDTA-chitosan conjugate for the enhancement of oral protein delivery [23]. In this patent, the covalent attachment of EDTA to chitosan was achieved by the formation of amide bonds between carboxylic acid groups of the polymer. Another example of an absorption enhancers are cell penetrating peptides (CPPs). Coadministration of cell penetrating peptides (CPP) with the peptide drug helps in the intracellular delivery of the macromolecules. Examples of CPPs used include: HIV-1 Tat, penetratin and oligoarginine [41]. A 
study conducted by Liang et al. (2005) on the enhancement of the oral bioavailability of insulin showed the use higher oral bioavailability of fluorescent isothiocyanate labelled insulin covalently conjugated to HIV-1 tat fusion protein compared to the native peptide. Intestinal absorption across the intestinal epithelium showed the conjugate of insulin and TAT was 5-8 times higher than that of free insulin [42]. Fatty acids and glycerides are another class of absorption enhancers that can act as detergents or surfactants, which temporarily disrupt the phospholipid membrane, improving substance penetration through the affected membrane [43]. Studies on sodium dodecyl sulfate, sodium caprate, and long-chain acylcarnitines shows increased permeability through the paracellular pathways [44]. Tomita et al. and Lindmark et al. proposed that sodium caprate is able to activate phospholipase C, causing upregulation of $\mathrm{Ca}^{2+}$, which is able to open tight junctions and hence improve absorption $[45,46]$. The drawback of using absorption enhances, however, is the potential toxicity involved. Several reports have been made indicating that absorption enhancers can cause damage, or enter the systemic circulation due to their low molecular mass leading to systemic toxicity $[47,48]$.

\section{Microemulsions}

Microemulsions are defined as isotropic, thermodynamically stable transparent systems composing of oil, water, surfactant and sometimes, co-surfactant forming particles with droplet size of $<200 \mathrm{~nm}$ [49]. Microemulsions are typically classified into three classes or a combination of the three classes: oil-in-water (o/w), water-in-oil (w/o) and bicontinuous. The ratio of oil phase, aqueous phase, surfactant and in some cases the co-solvent in an emulsion determines the resulting type of emulsion formed. The type of microemulsion formed is also dependant on the type of surfactant used. Surfactants with a hydrophilic lipophilic balance (HLB) value $>12$ primarily favours the formation of $\mathrm{o} / \mathrm{w}$ emulsions whereas surfactants with a HLB value < 12 favours the formation of w/o emulsion [50]. The main advantages of microemulsions over colloidal systems such as suspensions and emulsions include: low viscosity, higher stability, improved solubility, ease of manufacturing, ease of upscale and improved bioavailability [50].

It has been reported by Wen et al. (2013) that microemulsions were successfully applied to enhance the oral bioavailability of the tripeptide glutathione [51]. Other peptide drugs such as calcein and cyclosporin have also been reported to have improved oral bioavailability when administered in microemulsion form [52-54]. Naicker et al. observed enhanced drug bioavailability for microemulsions as well as a reduction in adverse effects associated with the administration of cyclosporin A. The bioavailability another peptide, SK\&F-106760, was also observed to be enhanced for microemulsion formulations when compared to the unformulated aqueous solutions [54]. In recent years, self-microemulsifying drug delivery systems (SMEDDS), which spontaneously emulsify when exposed to the fluids of the GI tract to form microemulsions, have been developed to enhance the oral bioavailability of protein drugs $[55,56]$. The study by Celebi et al. showed a $30 \%$ decrease in rat blood glucose levels after administering the lecithin-based microemulsion insulin formulation (Cilek, Celebi et al.). The use of large amounts of surfactant has been a concern regarding microemulsion formulations, as surfactants can cause toxicity.

\section{Nanoparticular Delivery Systems}

\section{Liposomes}

Liposomes are aqueous filled structures surrounded with one or more double layers of phospholipids or other amphiphilic lipids. Liposomes are generally spherical in shape with a size ranging from $20 \mathrm{~nm}$ to $10 \mu \mathrm{m}$ and are classified into six different categories: small unilamellar vesicles (SUVs), large unilamellar vesicles (LUVs), multilamellar vesicles (MLVs), multivesicular vesicles (MVVs), oligolamellar vesicles (OLVs) and giant unilamellar vesicles (GUVs). Liposomes are useful as drug delivery methods due to the ability to carry both lipophilic drugs as well as hydrophilic drugs. Lipophilic drugs are included in the phospholipids bilayer for delivery whereas hydrophilic drugs are trapped inside the interior aqueous cavity (Figure 5). It has been suggested that drug loaded liposomes can be taken up by endocytosis, transcellular pathways $[57,58]$ as well as via Peyer's patches [59].

A study by Takeuchi et al. showed enhanced calcitonin absorption with chitosan coated liposomes when compared with uncoated liposome formulations [60]. Pectin-coated liposomes have been shown by Sanko et al. to exhibit improved calcitonin absorption and activity [61]. It was concluded that the polymer cross-linking coatings increased uptake due to the increased retention time of liposomes in the intestine due to the polymer's mucoadhesive properties [61]. A study using insulin as a model polypeptide, Iwanaga et al. showed that a coating of polyethylene glycol or mucin sugar moiety was able to cause a gradual decrease in glucose levels following oral administration in rat models [62]. A GlyPro-Gly tri-peptide analogue for the treatment of post traumatic brain injury was shown by Bickerdale et al. to be more readily absorbed and have higher oral bioavailability relative to a saline formulation as seen by the faster appearance of the peptide in blood and greater total AUC respectively [63].

\section{Nanoparticles}

Alternative particulate carriers, including nano- and microparticles, are often chosen to overcome the problems concerning stability and entrapment efficiency of liposomes. Nanoparticles and microparticles are polymer or lipid fabricated particles having a size range between $1-1,000 \mathrm{~nm}$ and larger than $1 \mu \mathrm{m}$, respectively. Nanoparticles are produced by attachment or entrapment of drug molecules to the polymeric nanoparticle. To overcome one of the concerns of the usage of non-degradable polymers as nanoparticles, biodegradable polymeric nanoparticles coated have been developed. Hydrophilic polymers such as poly(ethylene glycol) (PEG) are especially useful as they are known to be long-circulating particles and have been used as potential drug delivery devices. Such polymers have demonstrated ability to deliver proteins and peptides [64]. Other commonly used nanoparticles used for drug delivery include: poly(D,L-lactic-co-glycolic) acid (PLGA), gold, chitosan and gelatine [65]. The advantage of using nanoparticle formulations over other methods such as liposome formulations is the

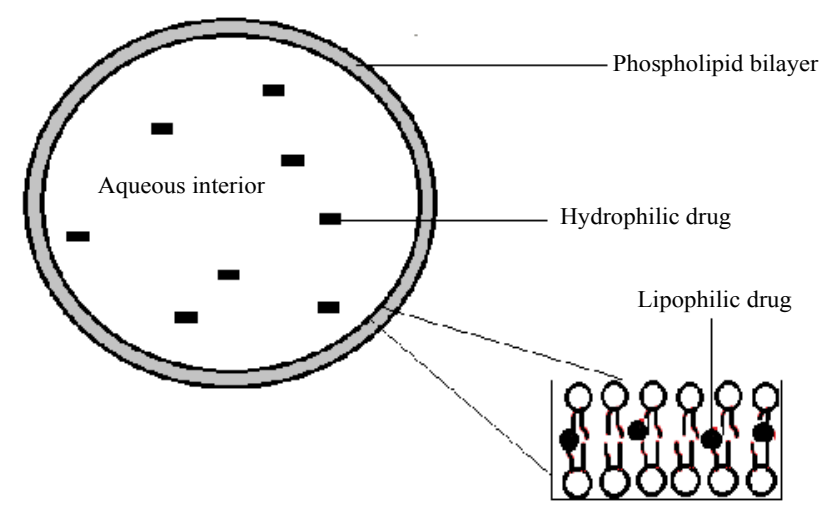

Figure 5: Diagram showing the distribution of drug in a liposomal carrier system. 
capability of controlled release in addition to the ability of improving drug stability, absorption and targeting [66,67].

A number of studies have demonstrated that nanoparticle drug formulations are able to improve oral bioavailability of peptides and proteins. The incorporation of calcitonin into nanoparticles, displayed enhanced oral bioavailability in rats and decreased calcium concentration in blood was observed as a result compared to the oral administration of unformulated calcitonin solution [68]. El-Shabouri et al. explored the use of chitosan nanoparticles to improve cyclosporin A absorption. The mucoadhesive properties of chitosan and reduction of the transepithelial electrical resistance caused opening of tight conjunctions and allowed the passage of smaller electrolytes $[40,69]$. Chitosan-nanoparticles have also been used in the development of oral insulin delivery systems [70,71]. Incorporation of destran sulphate (DS) into chitosan nanoparticles have shown longer circulation times and sustained release characteristics in addition to the improvement of bioavailability seen in chitosan only nanoparticles [60]. A study conducted by Prego et al. showed the use of a novel nanoparticle composed of chitosan chemically modified with PEG (PEG-Chitosan nanoparticles) for the oral delivery of salmon calcitonin. Addition of PEG improved the stability of the chitosan-based nanoparticle in gastrointestinal fluids as well as reducing nanoparticle cytotoxicity [72].

\section{Mucoadhesive Delivery Systems}

Most mucoadhesive delivery systems are formulated by using mucoadhesive polymers. Mucoadhesive polymers are multi-functional macromolecules, which in addition to their mucoadhesive properties increase the permeability of the drug candiates across epithelial membranes and simultaneously inhibit peptidolytic enzymes [73]. These polymers make close contact with the mucosal layer and therefore exert their effects within a limited area of the intestinal mucosa. Some of the mucoadhesive polymer/copolymers that have shown excellent bioadhesive properties include: sodium carboxymethyl cellulose, polyacrylic acid, tragacanth, polymethyl vinyl ether co-maleic anhydride, polyethylene oxide and methyl cellulose. Mucoadhesive delivery systems have increased residence time of the system at the absorptive mucosal membrane, leading to increased time available for absorption to occur and hence improved absorption of proteins and peptides [73]. Carbopol and polycarbophil show very good mucoadhesive properties at moderately acidic $\mathrm{pH}$ values. However, a major challenge posed for per-oral delivery is the presence of soluble mucin in the gastrointestinal luminal juices which deactivates the bioadhesive properties of these systems. Another limitation is the inability of the delivery systems to renew the mucoadhesive surface. Thus high mucus turnover rates impede prolonged adhesion to the mucosal surface.

\section{Colonic Drug Delivery}

Another strategy for oral peptide drug delivery is to target the colon. This is based on the premise that the overall peptidolytic or proteolytic activity of the colon is very low compared to that of the small intestine $[74,75]$. The residence time for a dosage form in this region of the gastrointestinal tract could also be relatively long (10-24 hours in rats), which may allow for the effective absorption of proteins and peptides $[76,77]$. Colonic drug delivery can be achieved by using $\mathrm{pH}$-dependant release dosage forms, time-controlled release formulations or to exploit the unique enzymes produced by microflora located in the colon. Azo-aromatic pro-drug conjugates have been found to be resistant to digestion in the stomach and small intestine. Azo-aromatic pro-drugs can be cleaved in the colon, releasing the peptide for absorption [78]. Pectin polymers are $\mathrm{pH}$ sensitive polymers that are insoluble at lower
$\mathrm{pHs}$ but dissolve in high and neutral $\mathrm{pH}$ environments. Coating of peptide drugs with $\mathrm{pH}$ sensitive polymers can protect the peptide drug from stomach environments. The $\mathrm{pH}$ range of the colon and small intestine, however are very similar and this reduces the site specificity of this method [79]. Time-controlled release systems are another potential method for colonic drug delivery. Time-controlled release is achieved with enteric coated time-release tablets utilising a hydroxyl propyl cellulose layer [78]. This method however is highly dependent on GI transit time, which can vary from person to person and be affected by diet and GI related diseases [80].

\section{Conclusion}

The enzymes in the GI tract are specifically designed to break down proteins and peptides into their amino acid counterparts resulting in the low oral bioavailability for the peptide drug that is observed. Researchers have devised and improved upon various methods to improve the oral bioavailability of peptide drugs including the use of penetration enhancers, enzymatic inhibitors, formulation approaches such as liposomes, nanoparticulates, microemulsions, mucoadhesive polymers and colonic delivery. Chemical modification methods including peptide analogue design, peptide pro-drug design, cyclisation and PEGylation have also been focused areas of research for the improvement of peptide drug oral bioavailability. Modest success in improving peptide oral bioavailability have been displayed by such approaches, however, only a very limited number of peptide drugs are in current clinical use in oral formulation forms. Among these approaches, the chemical modification seems to elicit the pathway to administrate peptide drugs orally as this method can enhance both peptide drug enzymatic stability and permeability in vivo. Chemical modification, as well as the combination of chemical modification methods with other synergistic strategies shows the most potential in achieving successful oral delivery of peptide drugs as seen in many examples, most noticeably in the work conducted by Bickerdike et al.

\section{References}

1. Thayer AM (2011) Improving Peptides. Chemical \& Engineering News Archive 89: 13-20.

2. Adessi $C$, Soto $C$ (2002) Converting a peptide into a drug: strategies to improve stability and bioavailability. Curr Med Chem 9: 963-978.

3. Collington GK, Hunter J, Allen CN, Simmons NL, Hirst BH (1992) Polarized efflux of 2',7'-bis(2-carboxyethyl)-5(6)-carboxyfluorescein from cultured epithelial cell monolayers. Biochem Pharmacol 44: 417-424.

4. Humphrey MJ, Ringrose PS (1986) Peptides and related drugs: a review of their absorption, metabolism, and excretion. Drug Metab Rev 17: 283-310.

5. Modi NB (1994) Pharmacokinetics and pharmacodynamics of recombinant proteins and peptides. J Control Release 29: 269-281.

6. T Borchardt R, Jeffrey Aube, Siahaan TJ, Gangwar S, Pauletti GM (1997) Improvement of oral peptide bioavailability: Peptidomimetics and prodrug strategies. Adv Drug Deliv Rev 27: 235-256.

7. Kim DC, Burton PS, Borchardt RT (1993) A correlation between the permeability characteristics of a series of peptides using an in-vitro cell-culture model (caco2 ) and those using an in-situ perfused rat ileum model of the intestinal-mucosa. Pharmaceutical Research 10: 1710-1714.

8. Joseph JW, Kalitsky J, St-Pierre S, Brubaker PL (2000) Oral delivery of glucagon-like peptide-1 in a modified polymer preparation normalizes basal glycaemia in diabetic db/db mice. Diabetologia 43: 1319-1328.

9. Lalatsa A, Lee V, Malkinson JP, Zloh M, SchAtzlein AG, et al. (2012) A prodrug nanoparticle approach for the oral delivery of a hydrophilic peptide, leucine(5)enkephalin, to the brain. Mol Pharm 9: 1665-1680.

10. Hashimoto M, Takada K, Kiso Y, Muranishi S (1989) Synthesis of palmitoyl derivatives of insulin and their biological activities. Pharm Res 6: 171-176.

11. Wang J, Hogenkamp DJ, Tran M, Li WY, Yoshimura RF, et al. (2006) Reversible lipidization for the oral delivery of leu-enkephalin. J Drug Target 14: 127-136. 
12. Pinnen F, Cacciatore I, Cornacchia C, Mollica A, Sozio P, et al. (2012) CNS delivery of L-dopa by a new hybrid glutathione-methionine peptidomimetic prodrug. Amino Acids 42: 261-269.

13. Parmentier J, Thewes B, Gropp F, Fricker G (2011) Oral peptide delivery by tetraether lipid liposomes. Int J Pharm 415: 150-157.

14. Moradi SV, Mansfeld FM, Toth I (2013) Synthesis and in vitro evaluation of glycosyl derivatives of luteinizing hormone-releasing hormone (LHRH). Bioorg Med Chem 21: 4259-4265.

15. Wang W, Camenisch G, Sane DC, Zhang H, Hugger E, et al. (2000) A coumarinbased prodrug strategy to improve the oral absorption of RGD peptidomimetics. J Control Release 65: 245-251.

16. Chae SY, Jin CH, Shin HJ, Youn YS, Lee S, et al. (2008) Preparation, characterization, and application of biotinylated and biotin-PEGylated glucagon-like peptide-1 analogues for enhanced oral delivery. Bioconjug Chem 19: 334-341.

17. Augustijns PF, Bradshaw TP, Gan LS, Hendren RW, Thakker DR (1993) Evidence for a polarized efflux system in CACO-2 cells capable of modulating cyclosporin A transport. Biochem Biophys Res Commun 197: 360-365.

18. Nielsen DS, Hoang HN, Lohman RJ, Hill TA, Lucke AJ, et al. (2014) Improving on nature: making a cyclic heptapeptide orally bioavailable. Angew Chem Int Ed Engl 53: 12059-12063.

19. Hill TA, Lohman RJ, Hoang HN, Nielsen DS, Scully CC, et al. (2014) Cyclic Penta- and Hexaleucine Peptides without N-Methylation Are Orally Absorbed. ACS Med Chem Lett 5: 1148-1151.

20. Greenwald RB, Choe YH, McGuire J, Conover CD (2003) Effective drug delivery by PEGylated drug conjugates. Adv Drug Deliv Rev 55: 217-250.

21. Nojima Y, Suzuki Y, Iguchi K, Shiga T, Iwata A, et al. (2008) Development of poly(ethylene glycol) conjugated lactoferrin for oral administration. Bioconjug Chem 19: 2253-2259.

22. Nojima Y, Suzuki Y, Yoshida K, Abe F, Shiga T, et al. (2009) Lactoferrin conjugated with $40-\mathrm{kDa}$ branched poly(ethylene glycol) has an improved circulating half-life. Pharm Res 26: 2125-2132.

23. Bernkop-Schnurch A, Krajicek ME (1998) Mucoadhesive polymers as platforms for peroral peptide delivery and absorption: Synthesis and evaluation of different chitosan-edta conjugates. J Control Release 50: 215-223.

24. Maianti JP, McFedries A, Foda ZH, Kleiner RE, Du XQ, et al. (2014) Antidiabetic activity of insulin-degrading enzyme inhibitors mediated by multiple hormones. Nature 511: 94-98.

25. McClellan JB Jr, Garner CW (1980) Purification and properties of human intestine alanine aminopeptidase. Biochim Biophys Acta 613: 160-167.

26. Langguth P, Bohner V, Biber J, Merkle HP (1994) Metabolism and transport of the pentapeptide metkephamid by brush-border membrane vesicles of rat intestine. J Pharm Pharmacol 46: 34-40.

27. Yamamoto A, Taniguchi T, Rikyuu K, Tsuji T, Fujita T, et al. (1994) Effects of various protease inhibitors on the intestinal absorption and degradation of insulin in rats. Pharm Res 11: 1496-1500.

28. Kimura T, Sato K, Sugimoto K, Tao R, Murakami T, et al. (1996) Oral administration of insulin as poly(vinyl alcohol)-gel spheres in diabetic rats. Biol Pharm Bull 19: 897-900.

29. Kraeling MEK, Ritschel WA (1992) Development of a colonic release capsule dosage form and the absorption of insulin. Methods Find Exp Clin Pharmacol 14: 199-209.

30. Marschutz MK, Bernkop-Schnurch A (2000) Oral peptide drug delivery: polymer-inhibitor conjugates protecting insulin from enzymatic degradation in vitro. Biomaterials 21: 1499-1507.

31. Sudhakar Y, Kuotsu K, Bandyopadhyay AK (2006) Buccal bioadhesive drug delivery--a promising option for orally less efficient drugs. J Control Release 114: 15-40.

32. Nishihata T, Kim S, Morishita S, Kamada A, Yata N, et al. (1983) Adjuvant effects of glyceryl esters of acetoacetic acid on rectal absorption of insulin and inulin in rabbits. J Pharm Sci 72: 280-285.

33. Yamashita S, Saitoh H, Nakanishi K, Masada M, Nadai T, et al. (1985) Characterization of enhanced intestinal permeability - electrophysiological study on the effects of diclofenac and ethylenediaminetetraacetic acid. J Pharm Pharmacol 37: 512-513.
34. Figueiras A, Hombach J, Veiga F, Bernkop-Schnurch A (2009) In vitro evaluation of natural and methylated cyclodextrins as buccal permeation enhancing system for omeprazole delivery. Eur J Pharm Biopharm 71: 339-345.

35. Utoguchi N, Watanabe Y, Shida T, Matsumoto M (1998) Nitric oxide donors enhance rectal absorption of macromolecules in rabbits. Pharm Res 15: 870-876.

36. Siegel IA, Gordon HP (1985) Effects of surfactants on the permeability of canine oral mucosa in vitro. Toxicol Lett 26: 153-158.

37. Hoogstraate AJ, Senel S, Cullander C, Verhoef J, Junginger HE, et al. (1996) Effects of bile salts on transport rates and routes of fitc-labelled compounds across porcine buccal epithelium in vitro. J Control Release 40: 211-221.

38. Mahato RI, Narang AS, Thoma L, Miller DD (2003) Emerging trends in oral delivery of peptide and protein drugs. Crit Rev Ther Drug Carrier Syst 20: 153-214.

39. Sharma AK, Karthikeyan S, Sharma S, Yadav S, Srinivasan A, et al. (1998) Structures of buffalo and mare lactoferrins. Similarities, differences, and flexibility. Adv Exp Med Biol 443: 15-21.

40. Hejazi R, Amiji M (2003) Chitosan-based gastrointestinal delivery systems. J Control Release 89: 151-165.

41. Khafagy el-S, Morishita M (2012) Oral biodrug delivery using cell-penetrating peptide. Adv Drug Deliv Rev 64: 531-539.

42. Liang JF, Yang VC (2005) Insulin-cell penetrating peptide hybrids with improved intestinal absorption efficiency. Biochem Biophys Res Commun 335: 734-738.

43. Liu DZ, LeCluyse EL, Thakker DR (1999) Dodecylphosphocholine-mediated enhancement of paracellular permeability and cytotoxicity in Caco-2 cell monolayers. J Pharm Sci 88: 1161-1168.

44. Hochman J, Artursson P (1994) Mechanisms of absorption enhancement and tight junction regulation. J Control Release 29: 253-267.

45. Tomita M, Hayashi M, Awazu S (1995) Absorption-enhancing mechanism of sodium caprate and decanoylcarnitine in Caco-2 cells. J Pharmacol Exp Ther 272: 739-743.

46. Lindmark T, Kimura Y, Artursson P (1998) Absorption enhancement through intracellular regulation of tight junction permeability by medium chain fatty acids in caco-2 cells. J Pharmacol Exp Ther 284: 362-369.

47. Kumar TR, Soppimath K, Nachaegari SK (2006) Novel delivery technologies for protein and peptide therapeutics. Curr Pharm Biotechnol 7: 261-276.

48. Bernkop-Schnurch A, Hoffer MH, Kafedjiiski K (2004) Thiomers for oral delivery of hydrophilic macromolecular drugs. Expert Opin Drug Deliv 1: 87-98.

49. Schulman JH, Stoeckenius W, Prince LM (1959) Mechanism of formation and structure of micro emulsions by electron microscopy. J Phys Chem B 63: 1677 1680.

50. Talegaonkar S, Azeem A, Ahmad FJ, Khar RK, Pathan SA, et al. (2008) Microemulsions: a novel approach to enhanced drug delivery. Recent Pat Drug Deliv Formul 2: 238-257.

51. Wen J, Du Y, Li D, Alany R (2013) Development of water-in-oil microemulsions with the potential of prolonged release for oral delivery of $L$-glutathione. Pharm Dev Technol 18: 1424-1429.

52. Ritschel WA (1991) Microemulsions for improved peptide absorption from the gastrointestinal tract. Methods Find Exp Clin Pharmacol 13: 205-220.

53. Constantinides PP, Scalart JP, Lancaster C, Marcello J, Marks G, et al. (1994) Formulation and intestinal-absorption enhancement evaluation of water-inoil microemulsions incorporating medium-chain glycerides. Pharmaceutical Research 11: 1385-1390.

54. Constantinides PP, Lancastera CM, Marcelloa J, Chiossonea DC, Ornera D, et al. (1995) Enhanced intestinal-absorption of an rgd peptide from water-in-oil microemulsions of different composition and particle-size. J Control Release 34: 109-116.

55. Trull AK, Tan KK, Tan L, Alexander GJ, Jamieson NV (1995) Absorption of cyclosporin from conventional and new microemulsion oral formulations in liver transplant recipients with external biliary diversion. $\mathrm{Br} \mathrm{J}$ Clin Pharmacol 39: 627-631.

56. Cilek A, Celebi N, Tirnaksiz F, Tay A (2005) A lecithin-based microemulsion of rh-insulin with aprotinin for oral administration: Investigation of hypoglycemic effects in non-diabetic and STZ-induced diabetic rats. Int J Pharm 298: 176-185.

57. Rawlings JM, Lucas ML, Russell RI (1987) Measurement of jejunal surface 
Citation: Yin N, Brimble MA, Harris PWR, Wen J (2014) Enhancing the Oral Bioavailability of Peptide Drugs by using Chemical Modification and Other Approaches. Med chem 4: 763-769. doi:10.4172/2161-0444.1000227

$\mathrm{pH}$ in situ by plastic $\mathrm{pH}$ electrode in patients with coeliac disease. Scand $\mathrm{J}$ Gastroenterol 22: 377-384.

58. Leserman L, Machy P, Leonetti JP, Milhaud PG, Degols G, et al. (1990) Targeted liposomes and intracellular delivery of macromolecules. Prog Clin Biol Res 343: 95-102.

59. Aramaki Y, Tomizawa H, Hara T, Yachi K, Kikuchi H, et al. (1993) Stability of liposomes in vitro and their uptake by rat Peyer's patches following oral administration. Pharm Res 10: 1228-1231.

60. Tsubery H, Mironchik M, Fridkin M, Shechter Y (2004) Prolonging the action of protein and peptide drugs by a novel approach of reversible polyethylene glycol modification. J Biol Chem 279: 38118-38124.

61. Nguyen S, Alund SJ, Hiorth M, Kjoniksen AL, Smistad G (2011) Studies on pectin coating of liposomes for drug delivery. Colloids Surf B Biointerfaces 88: $664-673$

62. Iwanaga K, Ono S, Narioka K, Morimoto K, Kakemi M, et al. (1997) Ora delivery of insulin by using surface coating liposomes - improvement of stability of insulin in gi tract. Int J Pharm 157: 73-80.

63. Bickerdike MJ, Thomas GB, Batchelor DC, Sirimanne ES, Leong W, et al. (2009) NNZ-2566: a Gly-Pro-Glu analogue with neuroprotective efficacy in a rat model of acute focal stroke. J Neurol Sci 278: 85-90.

64. Langer R (2000) Biomaterials in drug delivery and tissue engineering: one laboratory's experience. Acc Chem Res 33: 94-101.

65. De Jong WH, Borm PJ (2008) Drug delivery and nanoparticles:applications and hazards. Int J Nanomedicine 3: 133-149.

66. Jain A, Jain A, Gulbake A, Shilpi S, Hurkat P, et al. (2013) Peptide and protein delivery using new drug delivery systems. Crit Rev Ther Drug Carrier Syst 30: 293-329.

67. Mu L, Feng SS (2003) A novel controlled release formulation for the anticance drug paclitaxel (Taxol): PLGA nanoparticles containing vitamin E TPGS. J Control Release 86: 33-48.

68. Sakuma S, Suzukia N, Kikuchia H, Hiwatarib K, Arikawab K, et al. (1997) Ora peptide delivery using nanoparticles composed of novel graft copolymers having hydrophobic backbone and hydrophilic branches. Int J Pharm 149: 93-106.
69. El-Shabouri MH (2002) Positively charged nanoparticles for improving the oral bioavailability of cyclosporin-A. Int J Pharm 249: 101-108.

70. Pan Y, Li YJ, Zhao HY, Zheng JM, Xu H, et al. (2002) Bioadhesive polysaccharide in protein delivery system: chitosan nanoparticles improve the intestinal absorption of insulin in vivo. Int J Pharm 249: 139-147.

71. Cui F, Zhang L, Zheng J, Kawashima Y (2004) A study of insulin-chitosan complex nanoparticles used for oral administration. J Drug Deliv Sci Technol 14: 435-439.

72. Prego C, Torres D, Fernandez-Megia E, Novoa-Carballal R, Quinoa E, et al. (2006) Chitosan-PEG nanocapsules as new carriers for oral peptide delivery. Effect of chitosan pegylation degree. J Control Release 111: 299-308.

73. Vyas SP, Venugopalan P, Sood A, Mysore N (1997) Some approaches to improve bioavailability of peptides and proteins through oral and other mucosal routes. Pharmazie 52: 339-345.

74. Saffran M, Kumar GS, Savariar C, Burnham JC, Williams F, et al. (1986) A new approach to the oral administration of insulin and other peptide drugs. Science 233: 1081-1084.

75. Yamamoto A, Taniguchi T, Rikyuu K, Tsuji T, Fujita T, et al. (1994) Effects of various protease inhibitors on the intestinal absorption and degradation of insulin in rats. Pharm Res 11: 1496-1500.

76. Davis SS (1992) Developing delivery systems for peptides and proteins. in Scrip Magazine 34-38.

77. Bai JP, Chang LL, Guo JH (1995) Targeting of peptide and protein drugs to specific sites in the oral route. Crit Rev Ther Drug Carrier Syst 12: 339-371.

78. Hita V, Singh R, Jain SK (1997) Colonic targeting of metronidazole using azo aromatic polymers: Development and characterization. Drug Delivery 4: 19-22.

79. Ashford M, Fell J, Attwood D, Sharma H, Woodhead P (1993) An evaluation of pectin as a carrier for drug targeting to the colon. $\mathrm{J}$ Control Release 26 213-220.

80. von der Ohe MR, Camilleri M, Kvols LK, Thomforde GM (1993) Motor dysfunction of the small bowel and colon in patients with the carcinoid syndrome and diarrhea. N Engl J Med 329: 1073-1078. 